\title{
Management of Root Perforation due to Internal Resorption: A 1-year Follow-up Study
}

\author{
Aman Deep ${ }^{1}$, Seema Thakur ${ }^{2}$, Parul Singhal ${ }^{3}$, Dipti Chawla ${ }^{4}$
}

\begin{abstract}
Diagnosing tooth resorption is critical for effective management. Internal resorption is a rare phenomenon, presenting with a pathognomonic clinical sign of a "pink spot" in the crown. In case of infection-induced tooth resorption, endodontic therapy needs to be carried out to decrease bacterial load within the pulp space and facilitate repair of resorbed tooth structure. Following inflammation of the pulpal tissue, clastic cells infiltrate the pulp chamber along with physiological blood supply and thereby initiate the process of internal tooth resorption. Tooth resorption involves two phases: an initial injury phase and the subsequent stimulation phase. The injury phase pertains to the pulpal tissue getting injured by a noxious stimulus, whereas stimulation is caused by the infection present in the vicinity of the tooth. Additionally, in a case where the resorption is caused due to trauma, a multidisciplinary approach becomes imperative so that the long-term solution is achieved. This paper presents a case with internal resorption with a poor prognosis. However, surgical intervention was made to preserve the tooth until a definitive procedure can be instituted.

Keywords: Inflammatory root resorption, Mineral trioxide agglomerate, Replacement resorption, Resin-modified glass ionomer cement, Surgical management.

International Journal of Clinical Pediatric Dentistry (2021): 10.5005/jp-journals-10005-1992
\end{abstract}

\section{BACKGROUND}

Traumatic injuries invariably result in resorption of some sort to the dentition. As described by Andreasen, this can be internal which constitutes inflammatory, replacement root resorption, and external where surface resorption is present in addition to inflammatory and replacement root resorption. ${ }^{1}$ Although this condition is relatively rare, it is highly prevalent in avulsed teeth.

In internal inflammatory resorption, the loss of dentin keeps progressing until intervention is made, whereas in replacement resorption although resorption keeps occurring at a steady pace there is a subsequent deposition of hard tissue. This tissue more or less resembles quite similar to bone or cementum. ${ }^{2}$ The process of internal inflammatory root resorption can either perforate the tooth structure or remain enclosed within tooth space. Perforating internal resorption more often compromises the prognosis of the tooth as it invariably affects the strength of the tooth structure and also spreading the inflammation to the periodontal space and vice versa. ${ }^{3}$

Clinically, the condition may present as asymptomatic; however, it is identified remarkably by the presence of granulation tissue that hues gray-reddish underneath the translucent enamel at the cervical margin of the tooth. ${ }^{1}$ However, when viewed radiographically a large radiolucent enlargement of the pulp space is often seen.

A plethora of materials ${ }^{4}$ are available for the treatment of internal resorption and among all of these materials, mineral trioxide agglomerate (MTA) is the most frequently used material for repairing perforations, as it induces osteogenesis and cementogenesis followed by biodentin and glass ionomer cement. ${ }^{4}$

This paper describes a case involving perforating internal resorption following traumatic injury, which was managed and shows comparable healing after 1 year of the follow-up period.

\footnotetext{
${ }^{1-3}$ Department of Pediatric and Preventive Dentistry, Himacha Pradesh Government Dental College and Hospital, Shimla, Himachal Pradesh, India

${ }^{4}$ Department of Orthodontics, Bhojia Dental College and Hospital, Solan, Himachal Pradesh, India

Corresponding Author: Aman Deep, Department of Pediatric and Preventive Dentistry, Himachal Pradesh Government Dental College and Hospital, Shimla, Himachal Pradesh, India, Phone: +91 9736247471, e-mail: amdsingh91@gmail.com

How to cite this article: Deep A, Thakur S, Singhal P, et al. Management of Root Perforation due to Internal Resorption: A 1-year follow-up Study. Int J Clin Pediatr Dent 2021;14(4):593-595.

Source of support: Nil

Conflict of interest: None
}

\section{Case Description}

A 12-year-old female patient came to the department with a blackish discoloration in the right upper front tooth region for 1 month (Fig. 1). Her previous dental history showed that she had

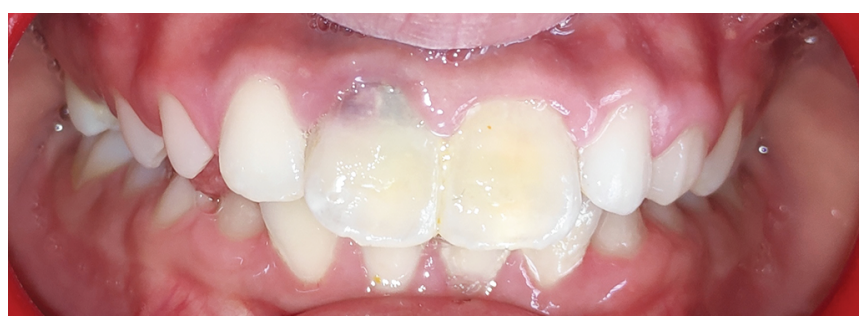

Fig. 1: Blackish discoloration appearing at cervical third in relation to right maxillary central incisor

() The Author(s). 2021 Open Access This article is distributed under the terms of the Creative Commons Attribution 4.0International License (https://creativecommons. org/licenses/by-nc/4.0/), which permits unrestricted use, distribution, and non-commercial reproduction in any medium, provided you give appropriate credit to the original author(s) and the source, provide a link to the Creative Commons license, and indicate if changes were made. The Creative Commons Public Domain Dedication waiver (http://creativecommons.org/publicdomain/zero/1.0/) applies to the data made available in this article, unless otherwise stated. 
undergone trauma when she was 8 years old. She suffered tooth avulsion wrt to right and left upper central incisors. Her previous records depict she was treated with rigid arch fixation and was following up for apexification procedure. However, currently patient started noticing reddish turned black discoloration in the right front tooth for the past 1 month. There was no history of pain or tenderness. On clinical examination, there was grade II mobility with discoloration at the cervical margin of 11. However, 21, appeared to be clinically stable and lacking any signs of inflammation. On radiographic examination, there appeared to be marked ovalshaped radiolucency involving radicular pulp space and coronal third as well (Fig. 2). Following which a diagnosis of inflammatory perforating internal resorption wrt 11 and replacement resorption wrt 21 was made. Consecutively, a treatment plan for surgical intervention wrt 11 was made.

The treatment objective was:

- To halt the process of root resorption wrt 11.

- To provide stability for 11 and preserve alveolar bone wrt 11 to later receive implant prosthesis.

The procedure was started by administering an infraorbital and nasopalatine nerve block along with local infiltration to provide for profound anesthesia. Now using a 15 no. BP Blade vertical incision was given on the labial aspect of the 11 and 12 region and an envelope flap was raised. The site was thoroughly irrigated with normal saline. Upon inspection, the labial cortex of the maxilla and the labial root surface of the right maxillary central incisor had undergone serve root resorption (Fig. 3). A $90 \%$ aqueous solution of trichloroacetic acid was applied over the resorptive lesion for 1 to 2 minutes using a cotton pellet. Following this, curettage of the resorbed cavity was done to remove any devitalized tissue. An 80-no. gutta-percha cone was placed within the canal over which freshly mixed white MTA Angelus (Dental Avenue India Pvt Ltd., Mumbai, India) was placed to provide for the root form (Fig. 4A). However, the cervical region of the crown defect was recontoured with resinmodified glass ionomer cement (GC Gold Label Inc. Corporation, Tokyo, Japan). The patient was prescribed analgesics along with antibiotic coverage and was recalled for suture removal after 1 week. Since the tooth manifested mobility, independent ligature wire splints were bonded to the tooth with their adjacent teeth. The glass ionomer cement placed at the cervical margin was later faced with filled composite resin (Fig. 4B). As for the status of 21, radiographically, it appeared that there was ingrowth of bone with the pulpal space and replacement resorption was ensuing (Fig. 4C). The patient reported for follow-up after 1 year (Fig. 5).

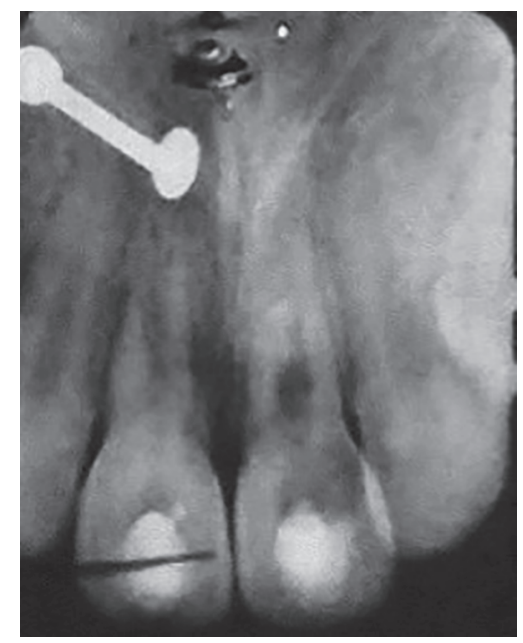

Fig. 2: Oval radiolucency at the coronal third and middle third of right maxillary central incisor

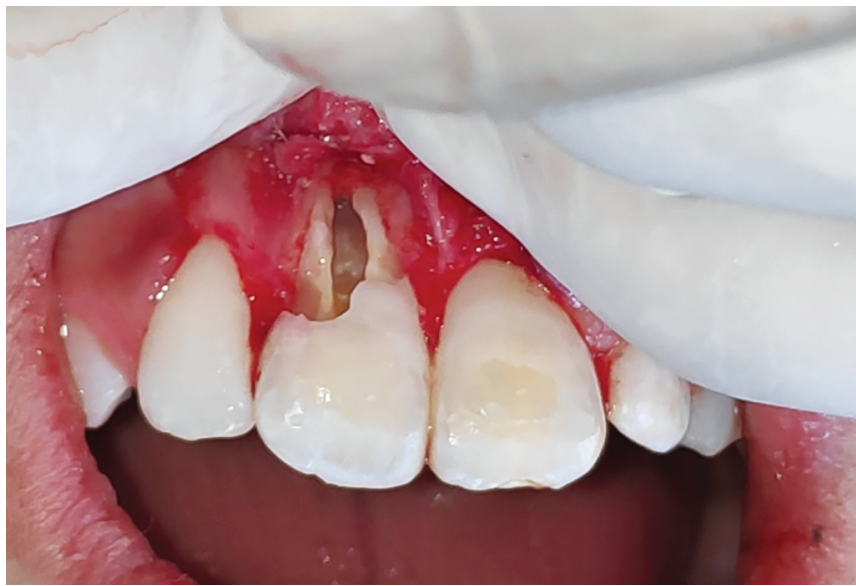

Fig. 3: Marked root resorption involving the labial cortex of 11
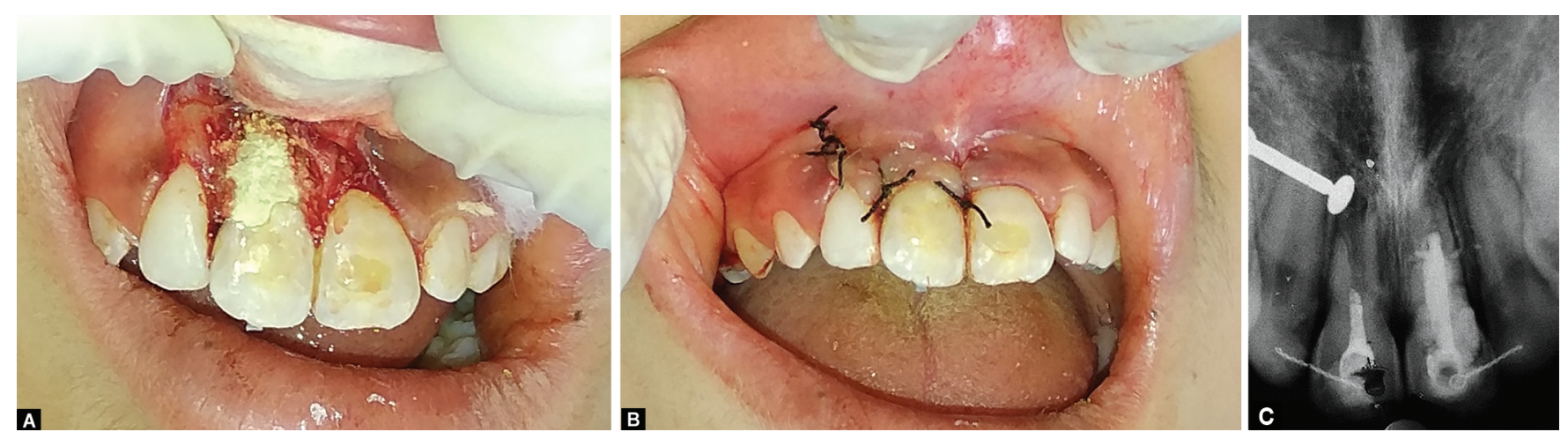

Figs 4A to C: (A) Placement of white MTA Angelus (Dental Avenue India Pvt Ltd., Mumbai, India) to provide for root form; (B) Sutured flap and restoration with RMGIC to provide for the contour of the crown on the right maxillary incisor; (C) IOPA shows gutta-percha within the root canal and MTA in relation to right maxillary central incisor and ingrowth of bony trabeculae and replacement resorption occurring in relation to left maxillary central incisor 

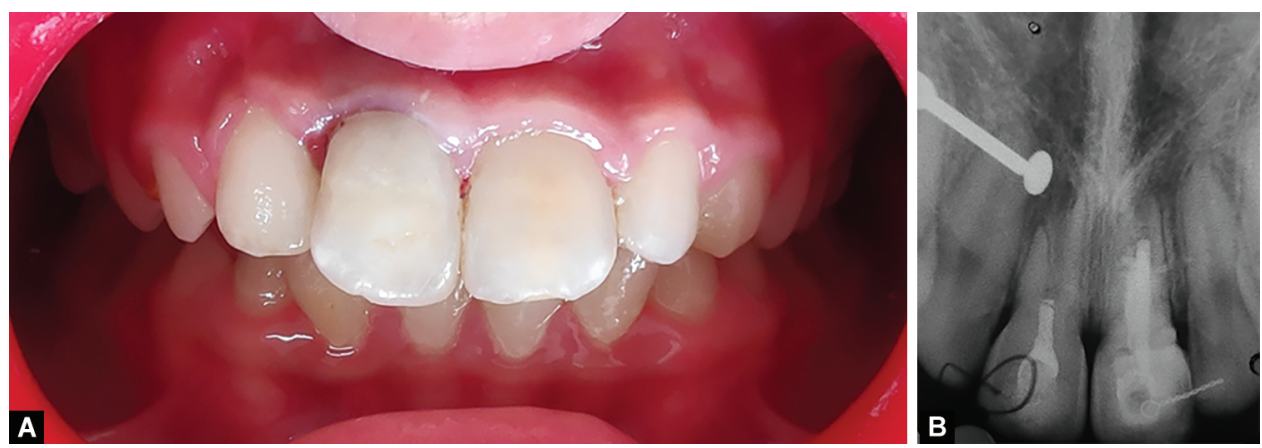

Figs 5A and B: (A) Intraoral frontal view after 1 year of follow-up; (B) IOPA after 1 year shows a marked decrease in radiolucency and a halt in the inflammatory process. Bone obliterating the root canals of maxillary central incisors at the apical third

\section{Discussion}

In teeth presenting with questionable prognosis, it is difficult to decide to whether endodontically treat that tooth or extract it. In the present case, although the definitive treatment remains to be extraction of the involved teeth with subsequent replacement with implant prosthesis. However, the age of the child and the growth anticipate, contraindicate the placement of implants. Hence, keeping in view the preservation of height of alveolar bone necessary for implant placement, it was decided to preserve the natural tooth until its replacement with an artificial prosthesis. ${ }^{5}$

Although curetting and restoration of the resorbed defect remain the traditional methods of managing resorption defects, topical application of trichloroacetic acid, followed by curettage and restoration is another method quite prominent in the literature. ${ }^{6}$ The use of this chemical provides hemorrhage control as trichloroacetic acid causes coagulation necrosis, and renders the resorptive tissue avascular, preventing its further recurrence.

Reviewing the literature, surgical management of a tooth presenting with resorptive lesions involving periodontal flap reflection and restoration of the defect with conventional restorative materials remains the preferred treatment option., ${ }^{7,8}$ However, this has a major pitfall as using conventional restorative materials compromises periodontal reattachment and, on the other hand, scientific evidence suggests the use of MTA or other bioactive materials in such situations facilitates new periodontal attachment. ${ }^{9}$ Henceforth, in the present case, we used MTA to restore the defect post removal of resorptive margins.

\section{Conclusion}

Internal resorption is an asymptomatic condition, which is invariably rapid and destructive. However, every effort should be made to preserve the natural tooth and halt the resorptive process, until definitive treatment is instituted.

\section{Clinical Significance}

Until the child matures skeletally implant prosthesis is universally contraindicated due to its proven sequelae of infraocclusion and altered gingival and alveolar contours. Hence, maintaining the natural tooth devoid of any inflammatory process to save the alveolar bone and provide for natural esthetics, surgical management of perforation internal resorption seemed to be a valid treatment option.

\section{References}

1. Tronstad L. Root resorption-etiology, terminology and clinical manifestations. Endod Dent Traumatol 1988;4(6):241-252. DOI: 10.1111/j.1600-9657.1988.tb00642.x.

2. Fernandes M, de Ataide I, Wagle R. Tooth resorption part I-pathogenesis and case series of internal resorption. J Conserv Dent 2013;16(1):4-8. DOI: 10.4103/0972-0707.105290.

3. Mittal S, Kumar T, Mittal S, et al. "Internal root resorption: an endodontic challenge": a case series. J Conserv Dent 2014;17(6):590593. DOI: 10.4103/0972-0707.144612.

4. Torabinejad M, Chivian N. Clinical applications of mineral trioxide aggregate. J Endod 1999;25(3):197-205. DOI: 10.1016/S00992399(99)80142-3.

5. Op Heij DG, Opdebeeck H, van Steenberghe D, et al. Age as compromising factor for implant insertion. Periodontol 2000 2003;33(1):172-184. DOI: 10.1046/j.0906-6713.2003.03314.x.

6. Heithersay GS. Management of tooth resorption. Aust Dent J 2007;52(1 Suppl):S105-S121. DOI: 10.1111/j.1834-7819.2007.tb00519.x.

7. Lustman J, Ehrlich J. Deep external resorption: treatment by combined endodontic and surgical approach. A report of 2 cases. Int Dent J 1974;24:203-206.

8. Goodman JR, Wolfe GN. The treatment of cervical external resorption in adolescents. Br Dent J 1980;149(8):234-236. DOI: 10.1038/ sj.bdj.4804500.

9. Pitt Ford TR, Torabinejad M, McHendry DJ, et al. Use of mineral trioxide aggregate for repair of furcal perforations. Oral Surg Oral Med Oral Pathol 1995;79(6):756-763. DOI: 10.1016/S1079-2104(05)80313-0. 